\title{
Developing Healthcare Team Observations for Patient Safety (HTOPS): Senior Medical Students Capture Everyday Clinical Moments
}

Elizabeth Susan Anderson ( $\square$ esa1@le.ac.uk)

University of Leicester College of Medicine Biological Sciences and Psychology https://orcid.org/00000002-2828-5680

\section{Leyshon Griffiths}

University of Leicester College of Medicine Biological Sciences and Psychology

\section{Teri Forey}

University of Leicester Medical School

\section{Fatima Wobi}

University of Leicester Department of Health Sciences

\section{Robert Norman}

University of Leicester Medical School

\section{Graham Martin}

The Healthcare Improvement Institute CambridgeScotland

\section{Research}

Keywords: Observational-practice, light-noise, good practice, poor practice

Posted Date: August 25th, 2020

DOI: https://doi.org/10.21203/rs.3.rs-59620/v1

License: (c) (1) This work is licensed under a Creative Commons Attribution 4.0 International License. Read Full License

Version of Record: A version of this preprint was published at Pilot and Feasibility Studies on August 23rd, 2021. See the published version at https://doi.org/10.1186/s40814-021-00891-3. 


\section{Abstract \\ Background}

Aviation has used a real-time observation method to advance anonymised feedback to the front-line and improve safe practice. Seeking a patient-safety experiential learning method for final year medical students we embarked on a pilot study for similarly observing real-time clinical practice in context.

\section{Methods}

Using Participatory Action Research, we collected data on medical students' observations of real time clinical practice. The observation data was analysed thematically and shared with a steering group of experts to agree a framework for recording observations. A sample of students (observers) and front-line clinical staff (observed) completed on-to-one interviews on their experiences. The interviews were analysed using thematic analysis.

\section{Results}

Thirty-seven medical students identified 917 issues in wards, theatres and clinics in an acute hospital Trust. They formed the themes of human factors, systems and environment. Aviation approaches were adapted to form an app capable of recording real time positive and negative clinical incidents. Five students and eleven clinical staff were interviewed and shared their agreement of the value of a process that helped them learn and has the potential to advance the quality of practice. Concerns were shared about how the observational process is managed.

\section{Conclusion}

The final product, an app called Healthcare Team Observations for Patient Safety (HTOPS), used by observing senior medical students can record both positive and negative clinical individual and team behaviours in acute-care practice. Early findings are promising as they highlight the totality of patient safety practice and can illuminate good and poor practice. The findings have been positively received and welcomed by the observed Hospital Trust. The next steps will further refine the app for use in all clinical areas for capturing light noise. HTOPS offers the opportunity for collective ownership of safety concerns without blame and has been positively received by staff and medical students.

\section{Background}

In the last decade, the analysis of patient safety events has led to the identification of circumstances which contribute to safe and unsafe patient care. ${ }^{1}$ These include not just active failings, but a wider range of more latent influences such as human factors, systems, aspects of the environment and poor 
professional practice. Interventions to address these contributory factors have led to some reduction in errors but high levels of concern remain. ${ }^{2-6}$ The analysis of data after safety events has been helpful, although accurate recording and understanding of the totality of patient safety data remains a challenge, as busy practitioners fail to report events, often because they are not shown the benefits. ${ }^{7-9}$ There are still big questions to be addressed about how to make changes that will advance standards for safe effective care. ${ }^{10}$

Mastering the complexity of healthcare delivery remains tortuous. Hard data for accountability purposes highlights variability in one area of practice at one moment in time but fails to assimilate and understand the integration of care delivery across all levels of an organisation. ${ }^{11}$ It often fails to pick up the nuances involved including the patient and practitioner perspectives. Triangulation of data to include patient and staff perceptions may offer a deeper understanding because it values users or front-line stakeholders as owners of the standards of their work. ${ }^{12}$ Findings from large-scale studies reveal that front-line practitioners need the right resources, including staffing levels, support and encouragement from leaders who are collaborative, values-based and uphold person-centred care. ${ }^{13}$ Practitioners also need simple holistic feedback about 'uncomfortable information' and the 'blind spots' that need to change. ${ }^{13,14}$ Data collection that is not meaningful to health care staff at all levels of an organisation can generate suspicion and resistance, and militate against the aspirations for building a safe culture for healthcare delivery. ${ }^{15}$ Calls for the next steps for patient safety seek greater clarity about how to identify and measure hazards in real time to intervene before incidents occur ${ }^{10}$ and to focus more attention on what works well learning from good practice. ${ }^{16,17}$ Moving from the reactive focus on the negatives, what goes wrong, towards a proactive focus on good practice requires a different approach to seeking and learning from clinical successes. Positive deviance highlights the success of individuals, teams and organisations and seeks to aspire others to adopt positive solutions to achieve effective safe practice. ${ }^{4}$ This requires a transparency and willingness to share and for others to adapt and adopt tested work patterns within their locality. ${ }^{11}$

Potentially valuable sources of knowledge, about the good and the potentially problematic features of care, are groups such as junior clinicians and medical students, who experience multiple settings and so have potentially unique comparative insight. The Francis and Keogh reports both suggested a special place for junior doctors and student nurses in identifying differences in standards of care between the organisations employing them, based on their simultaneous position as insiders and outsiders within the system. ${ }^{19-21}$ Ladden and colleagues (2006) considered the place of students who stand outside and yet are within every-day clinical practice and from this unique vantage point perceive what is going on; "Ask any medical resident or graduate nursing student working on the front lines of care about quality and safety problems and you had better be prepared to listen for a while. What they see is what we all read about. serious shortcomings in our systems of care - delays, errors, confused families, and daily workarounds to get patients what they need. Despite their frontline view of the problems, learners are almost never involved in workplace-based experiences to learn about systems improvement". ${ }^{22}$ Only 
recently have healthcare curricula been expected to deepen student understandings of patient safety at pre-registration/undergraduate level ${ }^{23-25}$, despite calls from the World Health Organization who have designed a patient safety curriculum guide. ${ }^{26,27}$ The General Medical Council (GMC), in asking for more teaching on patient safety, have highlighted some medical school programmes where students have been asked to observe what is happening in everyday practice. ${ }^{28}$ Despite this, many medical students remain unfamiliar with the scope of learning for safe practice. ${ }^{30}$ Transforming healthcare education and equipping students with the right approach is seen as one of the essential changes required, if we are to change culture and advance safe practice. ${ }^{10}$ An untested route to identify both good and poor quality care could emerge from proactive students. ${ }^{30}$ Students observe poor practice ${ }^{31}$ and could also anonymously highlight hazards in everyday practice and simultaneously advance their learning concerning patient safety.

\section{Background to the study}

Looking to advance medical student understandings of patient safety and aware that they are observers of the system, we were drawn to observation approaches used in aviation to inform best practice. Adopting learning from high risk industries for patient safety has already taken place within healthcare delivery. ${ }^{32,33}$ Our journey of discovery started with an aviation strategy to identify the contributory factors which underpin human error. This strategy known as the Line Operations Safety Audit (LOSA) is used to collect data about flight crew behaviour and situational factors on flights. The first audit was developed in the USA and has been internationally adopted. ${ }^{34,35}$ The findings collected over time have illuminated how people behave in real-time, offering evidence to improve safety. ${ }^{36,37}$ The attractions of this real-time observation reporting are that the data are collected prospectively and anonymised, with the results fedback to help change practice. This work has contributed to the flattened non-hierarchy team-based culture that characterises modern aviation. ${ }^{38}$ While acknowledging important differences between civil aviation and healthcare that are sometimes overlooked in efforts to import safety interventions from one context to the other, ${ }^{39}$ we nevertheless saw potential in adapting this approach with a view to both identifying influences on healthcare safety, and enriching undergraduate education. We outline the process of adaptation for medical student learning.

\section{Methods}

This exploratory research aimed to develop an observational recording process for patient safety learning by final year medical students. The design involved the cyclical collection of student observational data over three iterations, following the principles of Participatory Action Research (PAR), ${ }^{40}$ to reach a pragmatic approach for healthcare similar to that used in aviation. The cycles took place through three years of data collection. This year-on-year learning across successive student cohorts enabled changes to be made and in this way the student observations and interactions with real-time clinical events shaped the design of the final data repository mechanism. 
The student observational data was read by the academic researchers (ES and LG) for clarification and agreement with individual students halfway through the learning placement, to identify problems and issues in recording their observations. At the end of their observation period, students presented their findings for the first time to the clinical staff and senior patient safety leads. The recorded observations were collected and analysed for common themes using the principles of thematic analysis (ES and LG). 41

In the last cycle stakeholder perceptions and experiences of the process were collected using one-to-one semi-structured individual interviews with medical students (observers) and clinical teams (observed practitioners); using an independent researcher (FW). The interviews continued until theoretical saturation was reached. Interviews were guided by a topic guide focusing on the experiences of both the observers and the observed. With the consent of the participants all interviews were audio recorded and later transcribed and analysed using thematic analysis. In this way the experiences of the key-stakeholders were clarified.

This iterative process involved a research partnership between the stakeholders and researchers, overseen by a steering group (patients, students, a pilot, academics, clinicians with local patient safety leads). ${ }^{42,43}$ This study received ethical permission from University of Leicester and was funded by the Wellcome Trust.

\section{Results}

We present the development of the Healthcare Team Observation for Patient Safety (HTOPS) platform and process chronologically over three stages; the timeline can be seen in Fig. 1. The first stage combines the first two cycles of learning as this was an exploratory phase. The work was refined over these three years, and we reflect on key learning points that fed into the development and refinement of the system.

\section{Stages of the Observation Tool Development Stage One (2016-2017)}

The adaptation of the aviation observation process to identify patient safety concerns started with a Special Study Module (SSM) in 2016 and 2017 for final year medical students ( $n=11$ in each cohort; total $n=22$ ). We started with aviation terminology, namely 'Threats' observed in the working environment and 'Errors', i.e. perceived noncompliance with rules/policy/guidelines. In discussion with a clinical team (senior nurse and consultants from a local hospital), a set of possible healthcare Threats and Errors was agreed through a brainstorming exercise. They included a list of possible 'Threats' relating to human factors, technology and building/environment. The 'Error' list included noncompliance with rules relating to prescribing, ordering investigations and their interpretation, patient and practitioner communication etc. We gave a code number to each possible Threat and Error. The students were asked to complete 
observations in clinical areas, two theatres receiving for orthopaedic and urology, outpatient fracture clinics, ante-natal wards and clinics and medical wards. Students were given training on patient safety, observation techniques and the coding system template with the Threat and Error code list to record what they observed during a session (morning or afternoon) (Table 1). The students spent six days observing holistic clinical practice moving between their allocated ward, theatre or clinic.

\section{Evaluation Outcomes}

In 2016, students recorded a large number of observations and we analysed a subset of the data (21 scripts) for checking the process (Table 2). We found that students confused Threat and Error in 13 instances. We refined the paper recording sheet to enable students to write more narrative to justify their findings. In 2017, we analysed all the outcomes from the student observations ( $n=373$ observations); 43 were illegible and were withdrawn, leaving 330 for full analysis of observed care practice on wards, clinics and theatres, of which there were 22 errors (Table 3 ). Students continued to have difficulty in differentiating between Threats and Errors in the midst of the complexity of everyday clinical practice and found the codes cumbersome. However, they were able to step back and observe care delivery in real time, noticing a plethora of concerns relating to both sloppy practice (e.g. hand hygiene) and systems issues (e.g. caused by poor geography). All students reported they had advanced their understandings of patient safety. The observations revealed the students' lack of familiarity with the setting helped in identifying features that seemed inappropriate; whereas practitioners around them had normalised these practices. Some errors reported were incorrect and misleading, reflecting student unfamiliarity with speciality-specific safe practice.

The evaluation in 2016 and 2017 led us to the conclusion that the categories of Threat and Error were too simplistic to capture the complexity of healthcare environment and care delivery (Table 4).

We revised our categorisation framework to reflect clusters of themes identified in our analysis of the realtime student observations. There were termed Tags, as follows (Table 5):

Tag 1) Human Influences: The interactions amongst humans; 'what I do when I am with others' and other aspects of healthcare delivery. This includes the way in which one acts or conducts oneself professionally with patients and staff and individuals' physical actions performed incorrectly or not completed.

Tag 2) Work Environment: Relating to the physical layout/style and content within the building.

Tag 3) Systems: Things or parts that function together. The way humans interact with the environment including the level of staff required to function adequately to manage the clinical area.

To help identify the level of concerns each Tag was awarded a weighted Scale from 1 (a little concern) to 5 (a great deal). In addition, the Tag could relate to an individual scored as one person (A-Alone) or for 
practitioners working together in a Team $(T=$ Team $)$ of practitioners. At this stage we left these senior students to allocate the weight of concern following their patent safety training which explored never events and serious incidents.

\section{Stage Two (2018-2019)}

In 2018, seven students used the revised paper recording system and worked in pairs in clinical areas. Of the 638 recorded Tags, 123 duplicates (students recording the same observation) were removed. At this time a new electronic database for recoding the data was completed and these 515 safety concerns were transferred to the electronic system. These recordings contained 170 scores rated as ' 1 ' (low concern); 206 as ' 2 '; 107 as ' 3 '; 27 as ' 4 '; and 5 scored as serious, ' 5 ' (a great deal). The 5 serious Tags were all Human Influences $(\operatorname{Tag} 1)$ :

i. Complacency - Action: Description = Anaesthetic drug not labelled during a spinal epidural

ii. Confidentiality: Description $=$ Computer system open with patient results for everyone to see

iii. Action: Description = Sharps not disposed of correctly during a procedure

iv. Team Functioning: Description = surgical whiteboard incorrect documentation of use of needles during surgery

v. Team Functioning: Description = change in surgical list led to preparation in theatre for the wrong patient

The concerns from this analysis revealed that it was hard for students to rate the severity of patient safety concerns on a 5 point scale. For this reason it was decided to reduce the weight of the scale to two points. The steering group reflected on the student feedback and realised that students were also verbally reporting seeing positive excellent behaviour, which the recording system did not allow them to record. It was therefore agreed to capture all that students were seeing and record observations of good practice, resulting in a two negative $(-1$ and -2$)$ and two positive $(+1$ and +2$)$ weighted scale for the new app (Table 6 - App design).

\section{Sub-group 2018/2019 - new App}

A total of six final year medical students worked with the new app using iPads and similarly standing in a range of clinical areas (again theatres, clinics and wards) in an acute city hospital. Two students used and tested the app in December 2018 and working individually made 28 observations in two half-days. The remaining four final year medical students were trained to use the new app in June 2019. They each spent three half days and made a total of 72 recordings. Together these findings totalled 100 observations of which 68 were negative and 32 were positive, highlighting good practice. The majority were again relating to Human Influences. The app shows these outcomes in a variety of different ways (Fig. 2). 


\section{Evaluation of Stakeholder Perspectives}

Stakeholder perceptions were gained from five final year medical student 'observers' and 11 clinical staff members 'observed'. These were doctors of various grades, scrub nurses, Advanced Nurse Practitioners and nurse ward managers. The data are presented as themes and extracts (Table 7).

The value of the observation method for learning was confirmed by both the students who were observing practice and the observed practitioners. Front-line practitioners perceived the value of the recordings to enhance individual and team learning in clinical practice. For the clinical teams, the work was perceived as a supplement to existing data, such as safer surgery theatre checklists and clinical audits, because it could record a wider range of habitual practices and take account of environmental factors. It was felt that the observation process captured both good and poor practice which teams required for implementing appropriate improvements. The observed practitioners referred to 'a climate of negativity'around patient safety and praised the data for allowing the recording of positive clinical practice to provide both balance and an accurate representation of everyday practice. This was something they felt was lost with other recording practices which focused solely on poor practice. Shared learning across clinical areas was discussed as advantageous, particularly the ability to learn from areas showing excellence (Table 7).

Senior medical students perceived this as a good method for student learning on patient safety as they were forced to now see the totality of practice. As observers making the recordings they recognised that this process helped them to reflect on how to take on an active role within a clinical team. Several assitantship students who had qualified by the time they were interviewed described how their observations had fed into their plans for improving their practice.

Acceptability and impact of the observation process was discussed by front-line staff and students. The majority of practitioners were happy to be observed and confirmed that it was acceptable to be observed. Students felt equally comfortable observing all levels of staff grade. There were some concerns from mainly non-medical practitioners, who spoke about feeling additional pressure and being suspicious of being watched (Table 7). At the start of the observations practitioners being observed displayed a kind of Hawthorn effect. Their practice followed protocols and their behaviour was perceived as attentive showing very good practice. However, after a little while all staff quickly returned to practising unaware of being observed because they were busy. The medical students sensed the tensions and described adopting a friendly persona to gain practitioners' confidence and assert their position as helpful observers. Some students eased tensions by reminding observed clinical staff that they were ultimately looking at what they did as individuals but also within the systems and the environment where they were working.

Observed staff commented on the way the students introduced the work prior to commencing their observations. Some staff were not informed and unaware that observations were taking place as an 
exercise for patient safety and received limited information and, therefore, they felt threatened. In these situations students had to re-explain the project's purpose and the anonymity of the process to ease concerns. Some students defused tensions by offering informal feedback afterwards with everyone on the observed team. This, too, appeared to allay concerns. The acceptability of the observations greatly increased with clarity about the reasons behind the process.

The anonymity of observations was a strong theme. All staff were aware that observations were anonymised and valued this, but some were not convinced this was the way forward. In these instances practitioners wanted the observer to draw attention to malpractice, either by overstepping the line of 'observer' by intervening in real-time in the situation, or by having permission to report the action(s) after the event. Such an approach would, of course, mean that observations had the potential to have negative consequences to individual staff members, rather than being used to identify higher-level trends across departments. It was also suggested that observations featuring good practice might support doctors training portfolios by providing specific objective examples of their work.

The use of the observation data post-collection revealed that staff wished to receive information from the observations as soon after data collection as possible due to shift patterns and the rotation of staff and for immediately learning. Those requesting personal feedback on their individual performance also asked for this immediately after the observation session. Daily briefings conducted by teams were signalled as a place for rapid feedback to be shared and in this way staff felt any required changes were more likely to be implemented. This was compared to the delayed Trust information distribution in the form of emails and bulletins. Monthly team meetings were mentioned as a means of reinforcing information given during daily briefings as well as the appropriate environment for reflecting on data trends over time.

The mechanism for recording observations revealed a strong preference for the use of the electronic recording device. Students and staff who had experienced both paper and app recordings commented on their preferences. Visually, being seen with a clipboard was described as off-putting. In contrast, observers and observed staff overwhelmingly favoured the electronic device as these were now familiar to patients and clinicians within clinical environments and, thus, both acceptable and inconspicuous.

\section{Discussion}

In seeking to offer medical students deeper insights into safe practice we set out to design observational learning, adapting a method from aviation, for students to experience the complexity of being a member of a healthcare team in an acute hospital. Our students were tasked with looking for poor practice but told us they were also drawn to identify good practice. The final product, a recording app entitled Healthcare Team Observations for Patient Safety (HTOPS), has the potential to pick up what we term 'light noise', what is actually happening in real time, using an anonymous feedback system to record poor and excellent practice. The app presents a novel, non-threatening mechanism to identify low-grade risks to patient safety, while providing active learning on patient safety for medical students. We have evidence 
that students left their special study module with richer and deeper appreciations of everyday human foibles and weaknesses and possibilities for excellence, as soon to be members of care teams.

Teaching tomorrow's practitioners about safe practice, despite helpful directives, ${ }^{26,27}$ remains daunting. There are many social and psychological theories on human behaviour, ${ }^{44-48}$ challenges for whole cohort engagement with Quality Improvement ${ }^{49}$ and huge amounts of time and resources can be spent on poorly constructed simulations. ${ }^{50}$ Within the undergraduate curriculum we are experimenting with how to distil complex concepts and help inexperienced undergraduates appreciate the expansive levels of knowledge on patient safety. Many have perceived that students and junior staff can become the eyes and ears of an organisation, but as yet we have not harnessed this or considered using this as a teaching method, which enables students to become partners in propelling and contributing to optimal practice.

Our first challenge was to apply aviation observation methods to student learning within the complex systems of healthcare delivery - here the UK NHS. We sought to avoid designing yet another self-reported measurement tool, as there is a strong acknowledgement that healthcare staff feel overburdened with form-filling tools. ${ }^{51}$ Using Participatory Action Research, supported by a steering group with wide representation, ensured that our cyclical data was debated and discussed so that we moved from aviation thinking to healthcare thinking iteratively. Student willingness to learn more about patient safety using the medical school special study route yielded active participants, while the local acute hospital was more than willing to engage as partners in the project. The direction of travel was aided by an IT technologist seeking a simple yet workable solution, which required several paper prototypes before being applied to an app. The final product was found to be quick and easy to use and students could quickly enter and code both positive and negative observed patient safety behaviours.

Acceptability within clinical areas for student observations, despite team consent to be part of the research proved challenging. Some clinical practitioners welcomed being observed, while others were sceptical. Expecting qualifying students to explain their presence to unprepared seniors brought some concerns, although the students appeared to be confident to show and share the potential of the actions. Anonymity was paramount to acceptance because of avoiding a blaming of others culture, though some interview participants noted that this could limit the usefulness of feedback in making changes. Overcoming cultural challenges in healthcare and moving from the status quo remains a concern for patient safety leaders and will apply here, as 'trust' with this process remains essential paramount. There was a desire for instant feedback. This was because several leading clinical nurses and doctors could perceive this as a vehicle to help them advance good practice, not only because it picked up 'light noise' but also because it could highlight positive actions.

The final thematic analysis resonates with others who have tried to map the breadth and depth of contributory factors for patient safety. ${ }^{4}$ At this stage we do not claim this is complete and the iterative nature of this developments allows for on-going development and refinement. An essential responsibility for the usefulness of the intervention however, lies with the observer as they can write and clarify what they observe, offering not just factors but real time stories revealing more about the context. The next 
steps require further studies to i) confirm the app is complete and workable, ii) write a training and learning event for all observers, iii) explore the potential integration into everyday practice in clinical areas, and iv) affirm whether this changes practice and whether areas where possible poor practice is repeatedly identified do reflect and take this feedback on board. Finally, v) we need to confirm whether practitioners trust and are willing to invest in this method. It is possible to expand the observer role to include qualifying nurses and allied health practitioners and to qualified staff. The advantage here is that becoming an observer as a student appears to heighten the desire to be a good practitioner. Being qualified observer therefore could offer a chance for more senior practitioners to learn about human behaviour and relevant group theories, deepening their understanding of the theory of human behaviour in groups and human fallibilities. The concern is that deploying qualified staff as observers may evoke more suspicion amongst those being observed and that the methods would lose some of the naivety because of normalisation. On the other hand this might be better for speciality-specific safe practice.

This early pilot study has limitations. The small set of students were a self-selecting group of final year students who were keen to know more about patient safety. It is difficult to distinguish between their desire to increase their knowledge and actual commitment to observe seniors in real time clinical situations. Despite this three different groups of students all engaged with the project and produced comparable results. Much depended upon the thematic analysis of what was observed as students went onto the wards, and the final app will require further work and further testing to reach a more complete set of possible activities to be scored. Interviews with students and front-line staff were often compromised through participant availability within busy student and clinical working lives.

\section{Conclusion}

Patient safety remains the most important clinical challenge for modern healthcare delivery. Retrospective analysis of what goes wrong is now being aligned with real-time considerations for adaptive practice that ensures forward thinking. ${ }^{16}$ HTOPS offers a testable approach for learning. The process requires further study but this pilot data offers possible solutions not just for highlighting light noise but for deeper learning about safety because the process has the potential to link theory to practice.

\section{Declaration Of Interest Page}

\section{Ethical Permission}

This paper has ethical permission granted from the University of Leicester and this is reported in the paper (7741-esa1-medicaleducation). This paper does not have any animal or human data or tissues ("Not applicable").

\section{Authors Contributions}

Elizabeth Anderson has led this work, the field researcher was Fatimah Wobi, Teri Forey designed the app. All listed members of the research team have worked together throughout this project and have all helped 
to write this paper.

\section{Consent for Publication}

Not Applicable: We have no concerns for personal data in this paper

\section{Availability of data and materials}

Availability of data and materials are in the main shown in this document as they are contained within the tables. The tables summarise the paper reports of the medical students which are stored at the University of Leicester in a locked cupboard and are available for reference on request. The final set of data is available on the app on request for which we share a summary in the paper.

\section{Competing interests}

The authors have no competing interests.

\section{Funding}

This work was funded by the Wellcome Trist via the University translational funds.

\section{Conflict of Interest}

The authors report no conflicts of interest

\section{Author Contributions}

ESA, conceptualised the project and analysed and read all the student observations, LTRG, read and analysed all the student paper observations. TF designed the app and helped ES and LTRG import all the data into the app in the final cycle of testing. FW conducted the interviews with staff and students and with ESA analysed the qualitative data. RIN and GM were steering group members and analysed the project development throughout. All authors contributed to the writing and read and approved the final manuscript

\section{Acknowledgements}

We wish to thank University Hospitals of Leicester NHS Trust for their support in this project and particularly Moira Durbridge Director of Safety and the Medical Director Mr Andrew Furlong. We also wish to thank pilot Captain Colin Adair an aviation human factors trainer.

\section{References}

1. World Health Organisation. Making healthcare Safer. WHO Patient Safety and Risk Management: Geneva. Accessed 17 ${ }^{\text {th }}$ July: https://apps.who.int/iris/bitstream/handle/10665/255507/WHO-HISSDS-2017.11-eng.pdf;jsessionid=610C63F83825A4DD6E61AF14D9032079? sequence $=1$ 
2. Russ A, Fairbanks RJ, Karsh B, Militello LG, Saleem JJ. Wears, RL. The science of Human Factors: Separating fact from fiction. BMJ Qual Saf, 2013:22; 802-808.

3. Waterson P, Catchpole, W. Human factors in healthcare: welcome progress, but still scratching the surface. BMJ Qual Saf 2016;25:480-484.

4. Lawton R, Taylor N, Clay-Williams R, Braithwaite J. Positive deviance: a different approach to achieving patient safety. BMJ Qual Saf 2014;23:880-883

5. James JT. A new, evidence-based estimate of patient harms associated with hospital care. Journal of Patient Safety, 2-13: 9(3); 122-128

6. Pronovost PJ, Cleeman JI, Wright D, Srinivasan A. Fifteen years after to err is human: a success story to learn from. BMJ Qual Saf 2016 June 25(6): 396-9.

7. Macrae C. The problem with incident reporting. BMJ Qual Saf 2016;25:71-5.

8. Health Quality Ontario. Patient Safety Learning Systems: A Systematic Review and Qualitative Synthesis. Ont Health Technol Assess Ser [Internet]. 2017;17(3):1-23.

9. National Health Service Improvement. NRLS National Patient Safety Incident Reports: Commentary. London UK: NHS Improvement. 2018.

10. Ghandi TK, Kaplan GS, Leape L, Berwick DM, Edgman-Levitan S, Edmondson A, Meyer GS. Michaels D, Morath JM, Vincent C, Wachter R. Transforming concepts in patient safety: a progress report. BMJ Qual Saf 2018;27:1019-1026.

11. Mukammel DB, Header SF, Weimer DL. Top-down and bottom-up approaches to health care quality: the impacts of regulation and report cards Annula Rev Publ Health, 2-14;35: 477-497

12. Martin GP, McKee L, Dixon-Woods M. Beyond Metrics? Utilizing 'soft intelligence' for healthcare quality and safety. Social Science Medicine, 2015; 142: 19-26.

13. Dixon-Woods M, Baker R, Charles K. et al. Culture and behaviour in the English National Health Service: overview of lessons from a large multimethod study BMJ Quality \& Safety 2015;23:106-115

14. Collins SA, Couture B, DeBord Smith A, Gershanik E, Lilley e, Chang F. Yoon C, Lipstiz S, Sheikh A, Benneyan J, Bates DW. Mixed-methods evaluation of Real-time safety reporting by Hopistalised patients and their care partners: The MySafeCare application. J Patient Saf 2020; 16(2) e75-e81.

15. Armitage N, Brewster L, Tarrant C, Dixon R, Willars J, Power M, Dixon-Woods M. Taking the heat or taking the temperature? A qualitative study of a large -scale exercise in seeking to measure for improvement not blame. Soc Sci \& Med, 2018;198:157-164.

16. Hollnagel E. Safety-I and Safety-II. Farnham: Ashgate.2014

17. Woodward S. Moving toward a Safety II approach. Journal of Patient Safety and Risk Management 2019; 24(3) 96-99

18. Morrison EW. Employee voice behavior: integration and directions for future research. Acad Manag Ann, 2011;5:373-412.

19. Mid Staffordshire NHS Foundation Trust Public Inquiry. Report of the Mid Staffordshire NHS Foundation Trust Public Inquiry. Vol. 1. London: The Stationery Office, 2013. 
20. Keogh, Bruce. Review into the Quality of Care and Treatment Provided by 14 Hospital Trusts in England: Overview Report. London: NHS, 2013.

21. Ramanuj, Parashar Pravin, Howard Ryland, Edward W. Mitchell, Nassim Parvizi, and Krishna Chinthapalli. "In the Spotlight: Healthcare Inspections as an Opportunity for Trainee Clinicians to Be the Leaders of Today." BMJ Quality \& Safety 2014; 23(8): 706-8.

22. Ladden MD, Bednash G, Steves DP, N Moore GP. Educating interprofessional learners for quality, safety and systems improvement. Journal of Interprofessional Care, 2006;20(5):497-505.

23. Health Education England. Improving safety through education and training. Report by The commission in education and training for patient safety. 2016

24. Patient Safety Learning. A Patient Safety Future. A patient safety Learning Green Paper. London: Patient safety Learning. 2018.

25. General Medical Council. Outcomes for Graduates. London: GMC. 2018

26. World Health Organisation. Patient Safety Curriculum Guide. Multi-professional Edition. Geneva: WHO. 2011

27. World Health Organisation. Patient Safety Curriculum guide for medical students. Geneva: WHO. 2009.

28. General Medical Council. First, do no harm. Enhancing patient safety teaching in undergraduate medical education. GMC and Medical Schools Council: London. 2015

29. Batchelor A. Anderson E. Defining Patient Safety: A student perspective. Medi Sci Educator, 2019,29:399-408

30. Goldie J, Dowie A, Goldie A Cotton P, Morrison J. What makes a good clinical students and teacher? An exploratory study. BMC Medical Education, 2015; 15(40): 2-8.

31. Killam et al. Unsafe clinical practices as perceived by final year baccalaureate nursing students: Q methodology. BMC Nursing 2012, 11(26):2-13.

32. Heinrichs WL, Le Roy EB, Dev P. SBAR 'Flattens the Hierarchy' Among Caregivers. Studies in Health Technology and Informatics, 2012;173: 175-182.

33. Dekker SD. The field guide to understanding'Human Error'. Ashage: Farnham Surrey UK. 2014

34. International Civil Aviation Organisation. Line Operations Safety Audit (LOSA). Montreal Canada: International Civil Aviation Organisation.2002.

35. Federal Aviation Administration. Advisory circular 120-90. Line Operations Safety Audits. Washington DC: Federal Aviation Administration. 2006.

36. International Civil Aviation Organisation. Manuel of Evidence-based training. Montreal Canada: ICAO. 2013.

37. Tesmer B. LOSA Programme stimulates change that improves safety in line operations. International Civil Aviation Organization Journal, 2002; 57(4):13.

38. Dekker, SWA, Hugh TB, A just culture after mid-staffordshire. BMJ Qual Saf. 2014;23: 356-358. 
39. Neuhaus C, Hofer S, Hofmann G, Wächter C, Weigand MA, Lichtenstern C. “Perioperative Safety: Learning, Not Taking, from Aviation." Anesthesia \& Analgesia 2016; 122 (6): 2059-2063.

40. Kuper A, Reeves S, Levinson W. An introduction to reading and appraising qualitative research. 2008;337:a288

41. Braun V, Clarke V. Using thematic analysis in psychology. Qualitative Research in Psychology, 2006;39(2): 77-101.

42. Meyer J. Action research. In: PopeC, MaysN, eds. Qualitative research in health care. 3rd ed. Malden, MA: Blackwell Publishing, 2006:121-42.

43. McTaggart R. Reflection on the Purposes of Research, Action, and Scholarship: A Case of CrossCultural Participatory Action Research. Systematic Practice and Action Research, 1999; 12:493-511

44. Hall, P. Interprofessional teamwork: Professional cultures as Barriers. Journal of Interprofessional Care, 2005, Supplement 1: 188 - 196

45. Reeves S, Suter E, Goldman J, Martimianakis T, Chatalalsingh C, Dematteo D. A scoping review to identify organizational and education theories relevant for interprofessional practice and education.Calgary: Calgary Health Region. 2007.

46. Holden RJ.People or systems? To blame is human. The fix is to engineer. Prof Saf. 2009; 54(12): 3441.

47. Cordingley L, Peters S, Hart, J Rock J, Hodges L, McKendree J, Bundy, C. What Psychology do Medical Students Need to Know? An Evidence Based Approach to Curriculum Development, Health and Social Care Education, 2-13; 2(2);38-47.

48. Thomson K, Outram S, Gilligan C, Levett-Jones T. Interprofessional experiences of recent healthcare graduates: a social psychology perspectives on the barriers to effective communication, teamwork and patient-centred care. J Interprof Care. 2-15; 29:624-640.

49. Radenkovic D, Mackenzie R, Bracke S, Mundy A, Craig D, Gill D, Levi M. Involving medical students in service improvement: evaluation of a student-led, extracurricular, multidisciplinary quality improvement initiative. Advances in Medical Education and Practice, 2019:10 781-

50. Anderson ES \& Bennett S. Taking a closer look at undergraduate acute care interprofessional simulations: Lessons Learnt. Journal of Interprofessional Care. Accepted $1^{\text {st }}$ October 2019 https://doi.org/10.1080/13561820.2019.1676705

51. Hempel S, O’Hanlon C, Lim YW, Danz M, Larkin J. Rubenstein, L. Spread tools: a systematic review of components, uptake, and effectiveness of quality improvement toolkits, BMC, 2019

\section{Tables}

\section{Table 1: Stage One: Design for recording Observations (pilot 2016)}




\begin{tabular}{|c|c|c|c|c|c|}
\hline Sheet Number & & & & & \\
\hline Event & $\begin{array}{c}\text { Threat } \\
\mathrm{X}\end{array}$ & $\begin{array}{c}\text { Error } \\
\mathrm{X}\end{array}$ & $\begin{array}{l}\text { How event was managed and } \\
\text { outcome(s) }\end{array}$ & Lessons learned by observer & $\begin{array}{l}\text { Event } \\
\text { code }\end{array}$ \\
\hline & & & & & \\
\hline & & & & & \\
\hline & & & & & \\
\hline & & & & & \\
\hline & & & & & \\
\hline & & & & & \\
\hline & & & & & \\
\hline & & & & & \\
\hline & & & & & \\
\hline & & & & & \\
\hline & & & & & \\
\hline & & & & & \\
\hline & & & & & \\
\hline & & & & & \\
\hline & & & & & \\
\hline
\end{tabular}

Table 2: Stage One 2016 Examples (subset of 21 observation analysed 13 incorrect codes) 


\begin{tabular}{|c|c|c|c|c|}
\hline Code Theme & Description & $\begin{array}{l}\text { Error } \\
\text { or } \\
\text { Threat }\end{array}$ & $\begin{array}{l}\text { Student } \\
\text { correct in } \\
\text { E or T }\end{array}$ & Number \\
\hline \multirow[t]{3}{*}{ infection } & \multirow{2}{*}{$\begin{array}{l}\text { Consultant not washing hands between } \\
\text { patients }\end{array}$} & $\mathrm{T}$ & Incorrect & 1 \\
\hline & & $T$ & Correct & 1 \\
\hline & $\begin{array}{l}\text { Failure of medical staff to change } \\
\text { uniform/dress is a threat to other patients }\end{array}$ & & & \\
\hline $\begin{array}{l}\text { Insufficient } \\
\text { skills }\end{array}$ & $\begin{array}{l}\text { Operation where staff had not } \\
\text { recognised the drill setting before starting }\end{array}$ & $\mathrm{T}$ & incorrect & 1 \\
\hline Wrong patient & $\begin{array}{l}\text { Similar patients consultant confuses the } \\
\text { patients corrected by Registrar }\end{array}$ & $\mathrm{T}$ & Incorrect & 1 \\
\hline \multirow{3}{*}{$\begin{array}{l}\text { Privacy and } \\
\text { dignity }\end{array}$} & $\begin{array}{l}\text { Curtain not fully pulled around patient } \\
\text { during a ward round }\end{array}$ & $\mathrm{T}$ & Incorrect & 1 \\
\hline & (a) & $\mathrm{T}$ & incorrect & 1 \\
\hline & $\begin{array}{l}\text { Sensitive information spoken loudly at } \\
\text { the ward desk }\end{array}$ & & & \\
\hline Slow computers & issues with slow computers & $\mathrm{T}$ & correct & 1 \\
\hline Technology & No dicta-phone available & $\mathrm{T}$ & Correct & 1 \\
\hline Layout design & layout design of clinic & $\mathrm{T}$ & Correct & 1 \\
\hline Equipment & $\begin{array}{l}\quad \text { Needed help to identify the right } \\
\text { equipment before surgery- pieces missing. }\end{array}$ & $\mathrm{T}$ & Incorrect & 1 \\
\hline $\begin{array}{l}\text { Guidelines not } \\
\text { followed }\end{array}$ & $\begin{array}{l}\text { Changing uniform/clinical dress in } \\
\text { isolation wards between seeing different } \\
\text { patients }\end{array}$ & $\mathrm{E}$ & undefined & 1 \\
\hline $\begin{array}{l}\text { Poor } \\
\text { professionalism }\end{array}$ & veins & $\mathrm{T}$ & Incorrect & 1 \\
\hline $\begin{array}{l}\text { Confidentiality } \\
\text { and Patient } \\
\text { centred care }\end{array}$ & open Junior doctor dictating notes with door & $\mathrm{T}$ & Incorrect & 1 \\
\hline Checking & $\begin{array}{l}\text { Patient who was not sent his operation } \\
\text { date- took a year - administrative error }\end{array}$ & $\mathrm{T}$ & incorrect & 1 \\
\hline \multirow[t]{4}{*}{ Systems issues } & \multirow{2}{*}{$\begin{array}{l}\text { Transferring data from paper to IT } \\
\text { prescribing }\end{array}$} & $\mathrm{T}$ & Correct & 1 \\
\hline & & $\mathrm{T}$ & Incorrect & 1 \\
\hline & $\begin{array}{l}\text { The white Board was not up dated at } \\
\text { handover }\end{array}$ & $\mathrm{T}$ & Correct & 1 \\
\hline & $\begin{array}{l}\text { Bed shortages and problems with } \\
\text { transfer of patient back to wad from ITU }\end{array}$ & & & \\
\hline \multirow[t]{2}{*}{$\begin{array}{l}\text { Team } \\
\text { Communication }\end{array}$} & $\begin{array}{l}\text { Junior doctor not prepared for the ward } \\
\text { round and had to go back and gather more } \\
\text { data }\end{array}$ & $\mathrm{T}$ & Incorrect & 1 \\
\hline & & $\mathrm{T}$ & Correct & 1 \\
\hline
\end{tabular}


- Nurse joining a ward/team meetings out of sequence with which patient is being discussed and wrong information given corrected by consultant

\section{Excluded Data wrongly included Neither Error or Threat}

\begin{tabular}{ll}
$\begin{array}{l}\text { Error } \\
\text { or } \\
\text { Threat }\end{array}$ & Issues raised \\
\hline T & $\begin{array}{l}\text { Recorded as slow computers- whereas the installation of dictate software by a new clinician } \\
\text { is a normal process. If we had had a chat as a team this understanding about a normal } \\
\text { processes could have been relayed }\end{array}$ \\
\hline E & $\begin{array}{l}\text { Transfer of patient to the ward during the night from ITU is normal practice and within } \\
\text { Hospital protocol }\end{array}$ \\
\hline
\end{tabular}

Table 3: Cohort 2017: Summary outcomes (total 330 of which 22 errors)

Errors are highlighted in red 


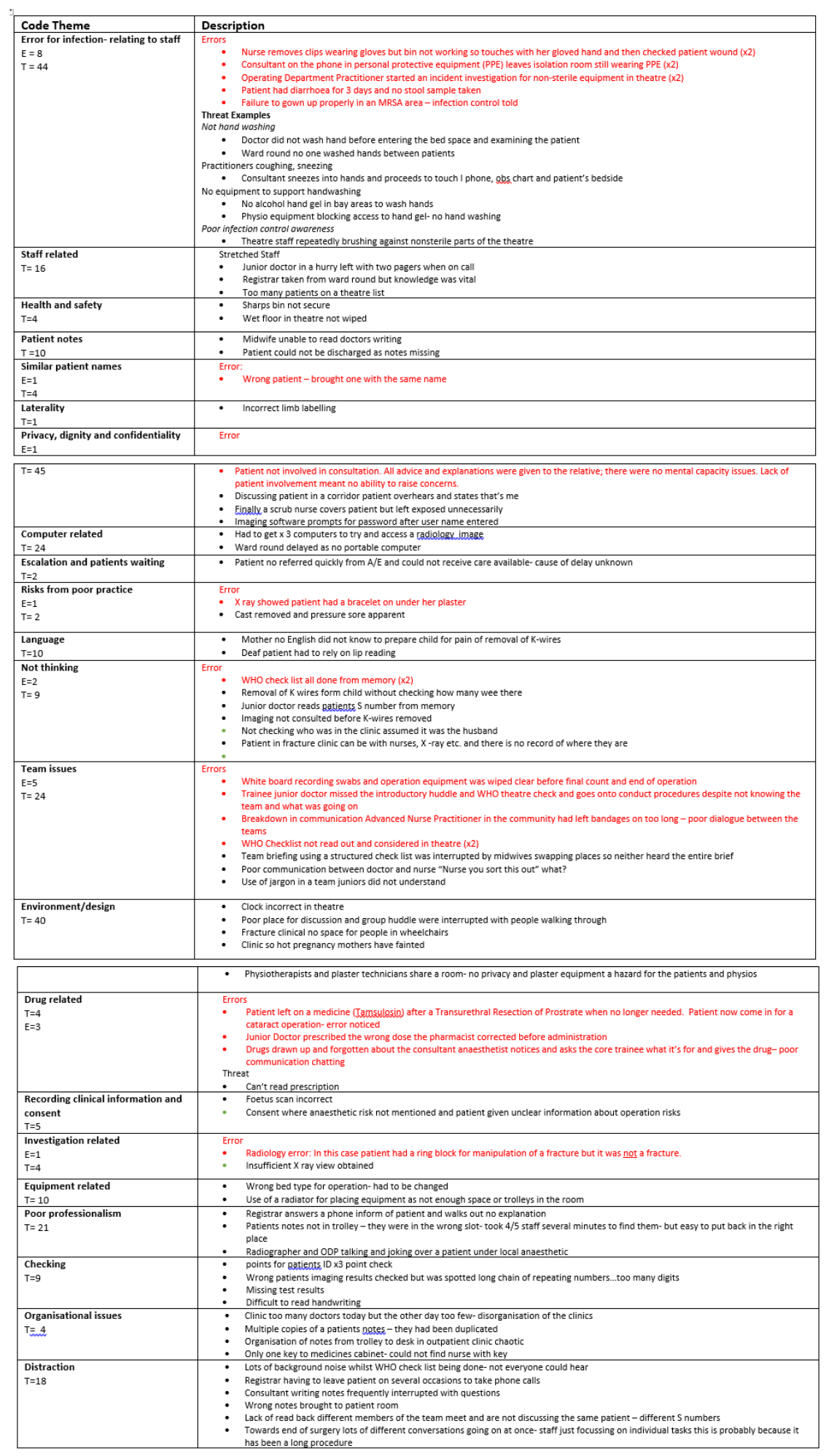

\section{Table 4: Complexity of Healthcare}

The complexity issues when comparing safety between Healthcare and Aviation 


\begin{tabular}{|c|c|c|}
\hline Comparators & Aviation Issues & Healthcare Issues \\
\hline \multirow{2}{*}{$\begin{array}{l}\text { The } \\
\text { environment }\end{array}$} & $\begin{array}{l}\text { The airplane structure varies } \\
\text { only slightly between models- } \\
\text { mostly this is about size. }\end{array}$ & \multirow{2}{*}{$\begin{array}{l}\text { Healthcare delivery takes place in the community } \\
\text { and in hospitals. In the community } \\
\text { primary/family medicine is available in health } \\
\text { centres. Hospitals consist of outpatient clinics, } \\
\text { wards, high dependency/ intensive care units, } \\
\text { emergency care and specific care sites such as } \\
\text { maternity. Clinical units for procedures and } \\
\text { theatres for operations; these areas have pre and } \\
\text { post assessment zones. There are specific staff } \\
\text { areas/rooms. }\end{array}$} \\
\hline & $\begin{array}{l}\text { The cockpit is separate and } \\
\text { distinct from the main part of } \\
\text { the plane accessed by the } \\
\text { public. In large airplanes, there } \\
\text { is a separate staff area. }\end{array}$ & \\
\hline $\begin{array}{l}\text { The } \\
\text { workforce }\end{array}$ & $\begin{array}{l}\text { The main workforce on the } \\
\text { airplane include the captain } \\
\text { and his deputies from one to a } \\
\text { possible } 4 \text { others and cabin } \\
\text { crew from one to a maximum } \\
\text { of } 27 \text {. There is also the ground } \\
\text { staff at airports who welcome } \\
\text { passengers and those who } \\
\text { supply and support the } \\
\text { mechanics of the airplane and } \\
\text { equipment and resources for } \\
\text { passengers. }\end{array}$ & $\begin{array}{l}\text { The Healthcare systems globally employ a vast } \\
\text { range of staff. Trained healthcare professional } \\
\text { includes doctors, nurses, pharmacists and allied } \\
\text { health professions in a range of different } \\
\text { positions of responsibility. These professional } \\
\text { practitioners work with a plethora of support } \\
\text { workers from receptionist to administrators, } \\
\text { scientists and many others. Health care involves } \\
\text { social care, policing, housing and other external } \\
\text { support public organisations including the } \\
\text { voluntary sector, families and/or carers. }\end{array}$ \\
\hline $\begin{array}{l}\text { Working } \\
\text { timeframes }\end{array}$ & $\begin{array}{l}\text { Air transport offers travel from } \\
\text { place A to place B. This line of } \\
\text { flight never varies, unless in an } \\
\text { emergency, although each route } \\
\text { is different and each airport. } \\
\text { The line is always the direction } \\
\text { of travel. The main risks are } \\
\text { take-off and landing but can } \\
\text { includes incidents during or } \\
\text { before and immediately after } \\
\text { flight. }\end{array}$ & $\begin{array}{l}\text { In healthcare patients may have similar } \\
\text { conditions but there is never a clear pathway or } \\
\text { journey of care for any one individual as everyone } \\
\text { is different. No two people are the same and no } \\
\text { two families/carers. The possibilities are endless } \\
\text { for involvement of different practitioners and } \\
\text { support staff. }\end{array}$ \\
\hline Policy & $\begin{array}{l}\text { Set and adhered to and } \\
\text { overseen by a few international } \\
\text { or national governing bodies } \\
\text { including International Civil } \\
\text { Aviation Organisation (ICAO), } \\
\text { European Authority in Safety } \\
\text { Aviation (EASA) and the UK } \\
\text { Civil Aviation Authority } \\
\text { (UKCAA). }\end{array}$ & $\begin{array}{l}\text { Each country operates different healthcare } \\
\text { systems some in the public domain (the NHS in } \\
\text { the UK - small private sector) some mainly } \\
\text { private (USA) and others are a mix of public and } \\
\text { private. Policies vary between systems and within } \\
\text { systems. In some systems, each hospital or unit } \\
\text { runs its own policies, which remain local to them. }\end{array}$ \\
\hline
\end{tabular}

\section{Table 5 - TAGGING FRAMEWORK HTOPS 2018}

TAG 1: Human Influences (including physical and emotional behaviour) 
Action Something you do not do or should not be doing and as such is an inappropriate action e.g. a procedure like handwashing. Propping a door open when it should be shut, needle stick injury, not putting sharps in the bin properly,

\section{Complacency}

Communication
FYI read patient $S$ number from memory, taking short cuts; e.g. being in a rush to go to the next patient in a ward round

Practitioners: Cannot read handwriting; Wiping the theatre board of patient data before theatre finished; Poor communication between doctor and nurse; poor introduction(s); poor incomplete handover; manipulative communication

Patients: Checking for ID/confirm who you are, incorrect name above the bed

Leaving computers open and unattended, leaving notes unattended. Talking about patients in public spaces with colleagues, or in-front of patients

Dignity

Leaving curtains open, patient exposed, patient hurt or caused some type of distress, patient pulled backwards in a wheel chair, patient referred to by room number condition, as 'him' or 'her'

Distraction

Something or someone who is distracting another, interruptions

Doing the Job

Prescribing, consenting, ordering, swab count, unlabelled specimen container, not writing clearly in the notes, using not up to date results, failure to ask about pain

Hygiene

Language

Leadership

Privacy

Professional
Infection control and risk - e.g. Hand washing

Practitioner e.g. foreign, using jargon, abbreviations

Patient e.g. foreign, deafness, disability dementia, disregard to cultural needs

Self-awareness, awareness of others, ability to praise or admonish another. Leadership in collaborative patient-centred teams. Poor involvement of the patient in the team

Overhearing private conversations, patient in ward hears what is being discussed at the ward desk

Decision making e.g. failure to use correct medication (lack of knowledge, missed allergy, wrong dose), medical interference e.g. unnecessary procedure test completed, not stopping a medication during surgical pathway; being unkind to a colleagues with loss of self-control; not acknowledging and listening to patient worries; lack of patient centredness. Civility, respect, responsibility for personal health.

\section{Situation Awareness}

Definition ="Our mental picture of what is happening around us and what is about to happen" (Mitchell, pg. 27). See issues about an individual or about the environment around you or the systems you are using. Wrong site for surgery. Staff complaining about their work life to patients. Counting swabs in memory not aloud
Skills

Stress and Fatigue

Team Functioning
Insufficient experience

Exhausted staff who are complaining they are not having breaks, short cuts taken. Staff, volatile emotions, poor moral

Clearly not relating to everyone in a team. Team fails to connect with one another; missing member of the team. 
TAG 2: Work Environment

\begin{tabular}{|ll|}
\hline Equipment & $\begin{array}{l}\text { No BP machine. Appropriate specialist equipment not available or working. Wet } \\
\text { plaster left on floor, phone issues, missing items in a theatre-pack }\end{array}$ \\
\hline Hardware: & $\begin{array}{l}\text { Furniture, physical component of a building and how it is cared for Air conditioning, } \\
\text { Cleanliness, Door propped open Wet floor, endoscope issues }\end{array}$ \\
\hline Layout/design & $\begin{array}{l}\text { Seating, Inadequate meeting space, Wrong bed type No wheel chair space } \\
\text { Software }\end{array}$ \\
$\begin{array}{l}\text { IT - computers and software used to support clinical activities Slow computer } \\
\text { responses, Not enough, No Wi-Fi on the ward, Mouse not working, Electronic } \\
\text { prescribing issues, Not logging off computer, ICE not working }\end{array}$ \\
\hline
\end{tabular}

\section{TAG 3: Systems}

\begin{tabular}{|c|c|}
\hline $\begin{array}{l}\text { Checking } \\
\text { Lists }\end{array}$ & Patient ID, WHO check list, Check lists \\
\hline Equipment & $\begin{array}{l}\text { Repairs and maintenance. How failures or broken things are fixed, charging of } \\
\text { electronic equipment }\end{array}$ \\
\hline Hand overs & Lost drug keys \\
\hline $\begin{array}{l}\text { Insufficient } \\
\text { staff } \\
\text { Skill mix }\end{array}$ & $\begin{array}{l}\text { Too few staff or too many; Inappropriate level of staff. Insufficient staff, No breaks } \\
\text { as not enough staff, Insufficient skill mix. Change over doctor, induction and } \\
\text { support for any staff. }\end{array}$ \\
\hline $\begin{array}{l}\text { Management/ } \\
\text { leadership }\end{array}$ & $\begin{array}{l}\text { Ordering materials for a ward/unit. Staff rota, clinic set up, are asset up. Access for } \\
\text { personal log in. Ordering materials and equipment. Who types us notes and who } \\
\text { knows. Case selection for the right clinician. }\end{array}$ \\
\hline Records & $\begin{array}{l}\text { Documentation/forms. How notes are accessed or made available; Appointments } \\
\text { and how they are made; Multiple copies of patient notes }\end{array}$ \\
\hline Transport & Ambulance and taxi issues \\
\hline
\end{tabular}

\section{Table 6: App Design}




\begin{tabular}{|c|c|c|}
\hline Field & Input & Design Decision \\
\hline Hospital & Select a single Hospital name & $\begin{array}{l}\text { As this is unlikely to change between } \\
\text { observations, this only needed to be set once per } \\
\text { session. }\end{array}$ \\
\hline Speciality & $\begin{array}{l}\text { Select a single } \\
\text { speciality/department }\end{array}$ & As above, only set this once per session. \\
\hline Area & $\begin{array}{l}\text { Select between Clinic, Ward, } \\
\text { Theatre, Pre/Post-Theatre and } \\
\text { Other. }\end{array}$ & $\begin{array}{l}\text { This selection needed to be made on each } \\
\text { observation as it is likely the observer would } \\
\text { move around between areas. }\end{array}$ \\
\hline Setting & Select either Team or Alone & $\begin{array}{l}\text { Quickly (single click) select whether it was } \\
\text { observed in a team or alone setting. }\end{array}$ \\
\hline Job Role & Select one or more job roles & $\begin{array}{l}\text { We had a broad list of possible job roles that } \\
\text { observers could select all the roles involved. }\end{array}$ \\
\hline Outcome & $\begin{array}{l}\text { Select either Strong Negative }(-) \text {, } \\
\text { Negative }(-) \text {, Positive }(+) \text { or Strong } \\
\text { Positive }(++)\end{array}$ & $\begin{array}{l}\text { By including positive observations we provided a } \\
\text { smaller and easier to use scale of outcome. }\end{array}$ \\
\hline Tags & $\begin{array}{l}\text { Select one or more descriptive } \\
\text { tags }\end{array}$ & $\begin{array}{l}\text { Similar to the job roles, this was a broad list of } \\
\text { tags that one or more could be selected to } \\
\text { describe the event. }\end{array}$ \\
\hline Description & Free text input & $\begin{array}{l}\text { The free text input is the slowest input, but is } \\
\text { required to clarify the observation. }\end{array}$ \\
\hline \multicolumn{3}{|c|}{ Additional Information } \\
\hline \multicolumn{2}{|c|}{$\begin{array}{l}\text { The input form was designed to be quick and easy to use, whilst also gathering as much } \\
\text { information as possible. }\end{array}$} & $\begin{array}{l}\text { The app was created as a hybrid application using the lonic framework and can therefore run } \\
\text { on both Android and iOS devices. }\end{array}$ \\
\hline \multicolumn{3}{|c|}{$\begin{array}{l}\text { The options for the Hospital, Speciality, Job Role and Tag fields are stored in an SQL database } \\
\text { on the server, which the mobile app accesses via an API on first logging in. This means that the } \\
\text { options can be edited at any point without having to update the app. }\end{array}$} \\
\hline \multicolumn{3}{|c|}{$\begin{array}{l}\text { To further speed up the data input, an observation can be incremented if it is observed more } \\
\text { than once. Also, each entry can be edited on the device if the observer ran out of time to enter all fields } \\
\text { in one go. }\end{array}$} \\
\hline \multicolumn{3}{|c|}{$\begin{array}{l}\text { Once the user is ready, all results on the app can be uploaded to the server, this requires } \\
\text { confirming the username and password are correct. Once uploaded, the observations are deleted from } \\
\text { the device. }\end{array}$} \\
\hline \multicolumn{3}{|c|}{$\begin{array}{l}\text { As the mobile app only connects to the server API on initial login and when uploading } \\
\text { observations, the majority of the time it will function offline - storing the data in an SQLite database } \\
\text { on the device. }\end{array}$} \\
\hline \multicolumn{3}{|c|}{$\begin{array}{l}\text { As well as needing a valid username and password to connect to the server, the app also } \\
\text { required the device to have a secure pin set. }\end{array}$} \\
\hline
\end{tabular}


Table 7: Qualitative Excerpts

Page 24/31 
The value of the observation method for learning

\section{Clinical team learning (sub-theme)}

'... you can also then look at areas of good practice and areas of poor practice and see is it that the areas of poor practice can learn from areas of good practice, because these observers can pick up areas of good practice as well. So the good thing is that they would highlight both, you can then compare and say why is it that it works well in one setting and a similar setting in another specialty, why doesn't it work so well?', H0O5.

I think it would be a good thing. I think it's one of the most important things that we can help with, patient safety, and I think it helps us to realise areas where there's potential to improve things. I think a lot of us are aware of things that could be improved but I think a lot of us aren't aware of other things that other people might pick up. $\mathrm{HOO6}$

'I think that's what we need to sort of like focus on because for too many years, it's always been very negative. And we need to highlight there's a lot of people out there doing a fabulous job, and they aren't highlighted enough, and that work isn't highlighted enough. And that's not me saying we don't need to look at the things that need to be improved, because that's essential, but we don't praise where praise is due. HOO9

\section{Student learning (sub-theme)}

'I think it makes you more vigilant in your own practice when you have to observe other people making those mistakes. So things like washing hands or putting patient detail away or something like that, like I feel like I'm more aware of myself in those settings because l've had to observe someone else.' SOO4
Acceptability and impact of the observation process

\section{Acceptable to be observed: Staff/Practitioner}

'The consultants weren't that bothered... they'd start to have comments like 'oh, patient safety whatever'... it was more the nurses and the ODPs who were a bit more like 'oh my God, we have to be careful'. SOO4

'I wasn't aware that I was watching different grades. I mean obviously I know I am but I wasn't, I didn't feel any different making observations from the consultants than from the HCA [Health Care Assistant] type thing', S001.

\section{Acceptability of being the observer :Students}

'...it felt in some ways like we were almost marking them which it's sort of the paradigm...that's essentially what it's done to us, if someone's standing there with a checklist, they're marking you and you can pass or fail... so there was that feeling of trying to accommodate for that, being almost overfriendly.' SOO2.

'...so I asked 'are you happy for me to be around?' and they said yes, but then I could clearly tell that they weren't and kept making comments about the fact that I was there and I was watching - I mean obviously it was difficult for me being in that situation. I didn't find it difficult for me but more for the other clinician she was working with because I think she was trying to sort of, she wanted someone to back her up and they were kind of 'well no, it's fine that she's there', so I could feel that there was a bit of tension there.' S001.

I felt very awkward because I could sense the anxiety and the discomfort surrounding my observations, especially when I used to put pen to paper, everyone used to kind of just like tense up and bit and then - then they wander around trying 
to see what I had written.... they were quite confrontational, it was just like 'what have you noticed?' or 'what are writing?' So they said to me they didn't feel comfortable with me writing things.' S004.

\section{Concerns for being observed: Staff/Practitioner}

'... with someone that observes, you always associate that with being critiqued... for someone else to watch you do it it's more nerve racking because you're thinking 'oh my God'you're double guessing what you would normally do in practice... And I think sometimes you're more likely to make errors because you're nervous.' H008, Nursing staff.

'Well personally I'm very used to it, having medical students in clinic sitting behind me, so that wasn't an issue. But I think I was more aware of what I was doing. I think it formalised me a little bit.' H001, Doctor.

....but it is a little bit nerve racking at times, you do second guess yourself and double check. But to be fair they were unobtrusive and I never felt, whether I was observed, I never really knew whether I was observed or not.' H007, Nursing staff.

\section{Concerns for being the observers: Students}

- I felt like I think it was the lack of prior notice that made them feel a bit more like they were being watched. Because obviously when you say patient safety I think what they assumed would be human factors down to them which made them more hostile. There's no other word for it really, or nervous. And so when, because one of the categories was equipment failures or shortages or understaffing and when I focused more on those things they were a lot more open about the struggles they're facing, because they felt like they were going to make a difference. S004

The process

of anonymity of observations

\section{Staff views on anonymity}

I presumed it was anonymous, however if they saw something that was particularly unsafe, you know, anywhere I would have hoped that they would have raised it and felt confident to raise it on the day rather than just to write it down that there was a problem.' H0O2

'I mean if nothing else, if it was all positive, it helps form part of your sort of professional development portfolio, it would help that, but actually if it raises some good points along the way and having it quite independent because a lot of people in their professional development portfolios, you know, it's fairly biased, I would argue. And actually having an independent student who would look at things slightly differently is useful I think'. HOO4

\section{The}

mechanism for recording observation

\section{Staff views}

'At the time they had paper but they're now trialling an electronic form. Which I think may have pros and cons. I think an iPad is quite acceptable. If they're doing it on their phone I think people think that they're texting and things like that. So phones don't go down very well...An iPad I think is generally more accepted as a learning tool. All the students now have iPads and it's more thought of if you're on an iPad that you're actually working'.HOO6

\section{Student views}

'I think in some ways it [the iPad] is more discrete. As students we have our iPads with us on placement anyway so it's not as obvious what we're doing. I think the clipboard itself can be quite threatening and yeah, so I think the iPads are a good idea'. SOO3 
The use of

the

observation

data post

collection

\section{Staff views}

'I think if it raises some points, you know, generally about things that people are doing subconsciously - or not doing subconsciously - and actually I appreciate it's anonymised but actually if someone's able to turn round and say 'do you realise you do this?', or don't do this, that's actually quite helpful.' HOO4

- I ' ' would personally want it fed back to myself as a Ward Sister. Now I have responsibility for this ward so if the practice is not of an expected standard I would like to know about that personally so I could disseminate it back to my team'. H009

- $\quad$ On the day, at the debrief, yeah, that would be great. I think that would be helpful in that situation rather than later on, when you've forgotten about it. H010

- 'We have briefings at the beginning of every list and if anything changes, so if we have different staff in the afternoon to the morning we have another briefing before the beginning of the afternoon list... yeah, there's plenty of time to feed it back. If it's something that's sort of happened during that procedure that they've noticed and they gave us feedback straight away, you can feed it straight back in the debrief. But if it was more that they wrote it down on their iPad and handed it in, then obviously by the time the next debrief it will be a completely different team. So more of like the trends of what they see over the two days of observing. I think we tend to have them once a month and also our consultants have a meeting as well. We also have like audit quality improvement [0:08:21] so that would be another place where students could actually come to that and present it themselves'. H0O6

\section{Figures}




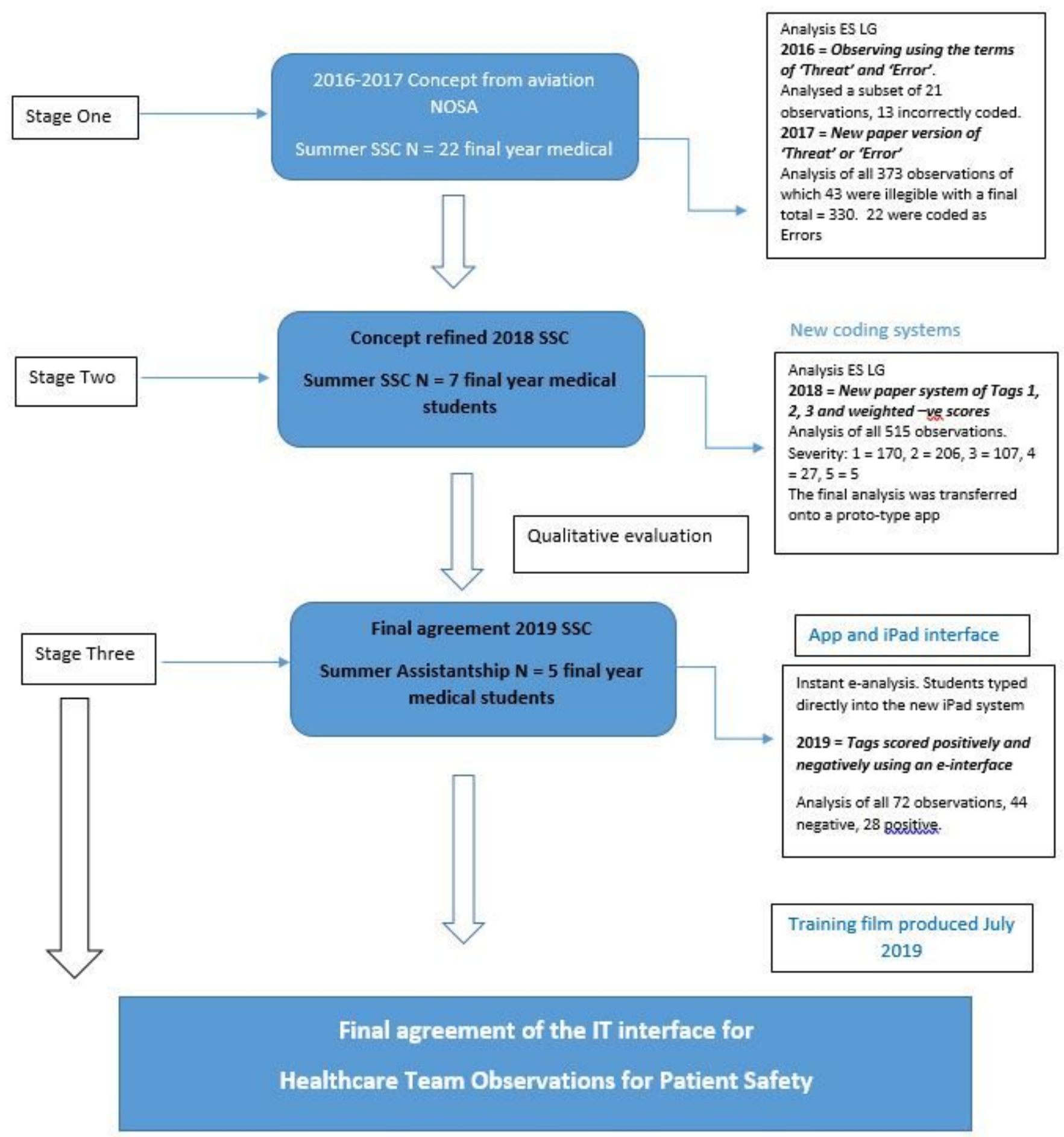

Figure 1

Time Line of the Development of Healthcare Team Observations for Patient Safety (HTOPS) 
40

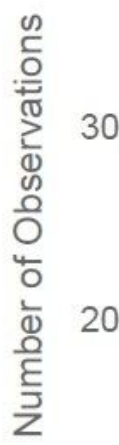

10

0

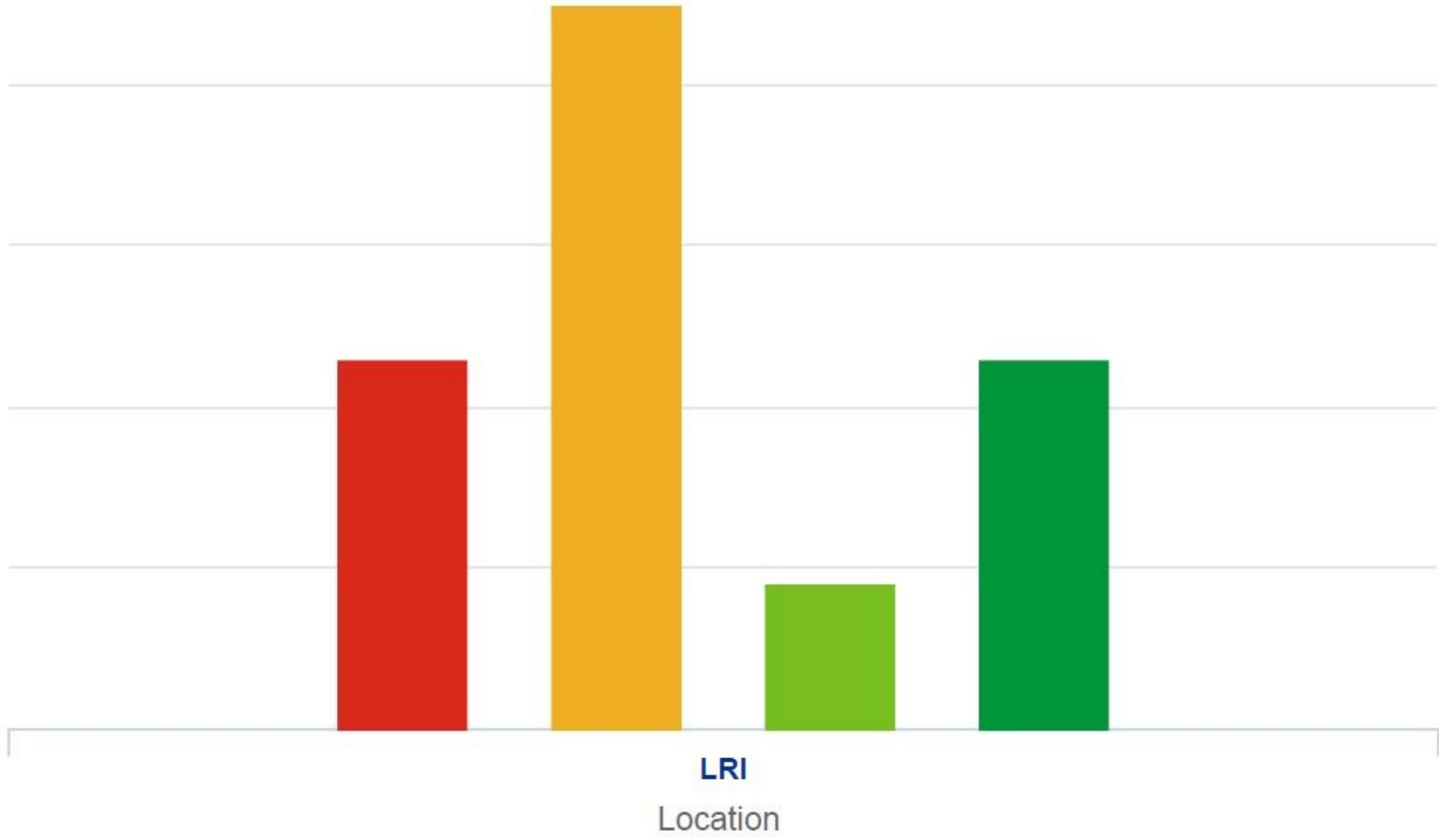

Very Negative

Negative

Positive

Very Positive

\section{Figure 2}

2 A: Data from iPad Observations in 2019 


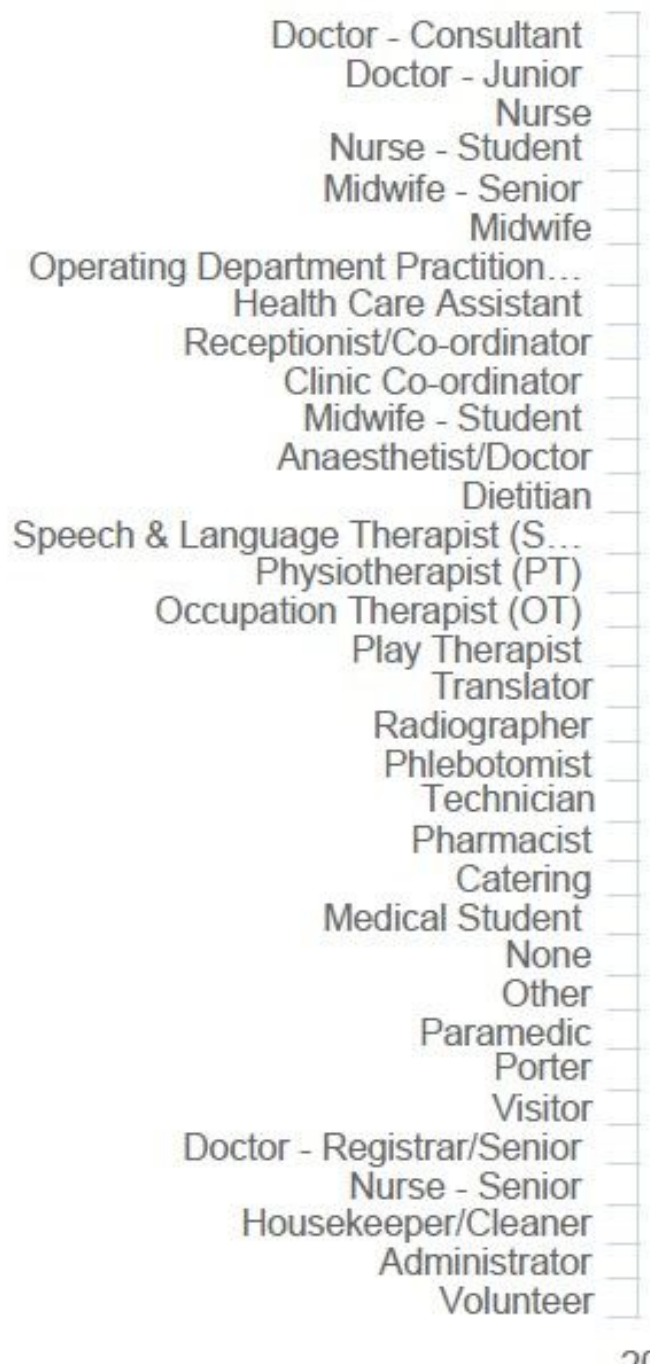

20

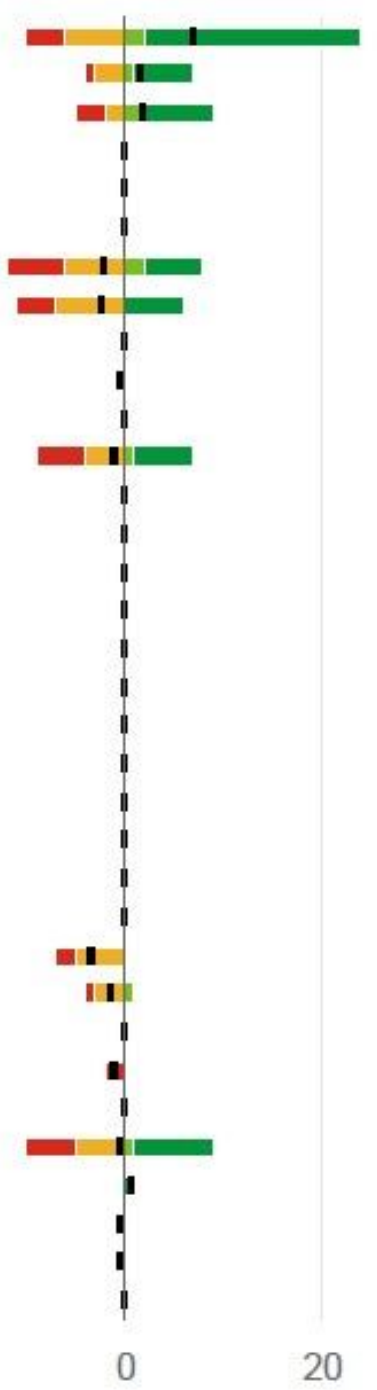

Number of Observations
Doctor - Consultant

Doctor - Junior

Nurse

Nurse - Student

Midwife - Senior

Midwife

Operating Department Practition...

Health Care Assistant

Receptionist/Co-ordinator

Clinic Co-ordinator

Midwife - Student

Anaesthetist/Doctor

Dietitian

Speech \& Language Therapist (S...

Physiotherapist (PT)

Occupation Therapist (OT)

Play Therapist

Translator

Radiographer

Phlebotomist

Technician

Pharmacist

Catering

Medical Student

None

Other

Paramedic

Porter

Visitor

Doctor - Registrar/Senior

Nurse - Senior

Housekeeper/Cleaner

Administrator

Volunteer

40

Number of Obst
Very Negative
Negative
Positive
Very Positive
$50 \%$

Highcharts.com

\section{Figure 3}

2B: 2019 Observations - Observed practitioner 


\section{Tag Collection}

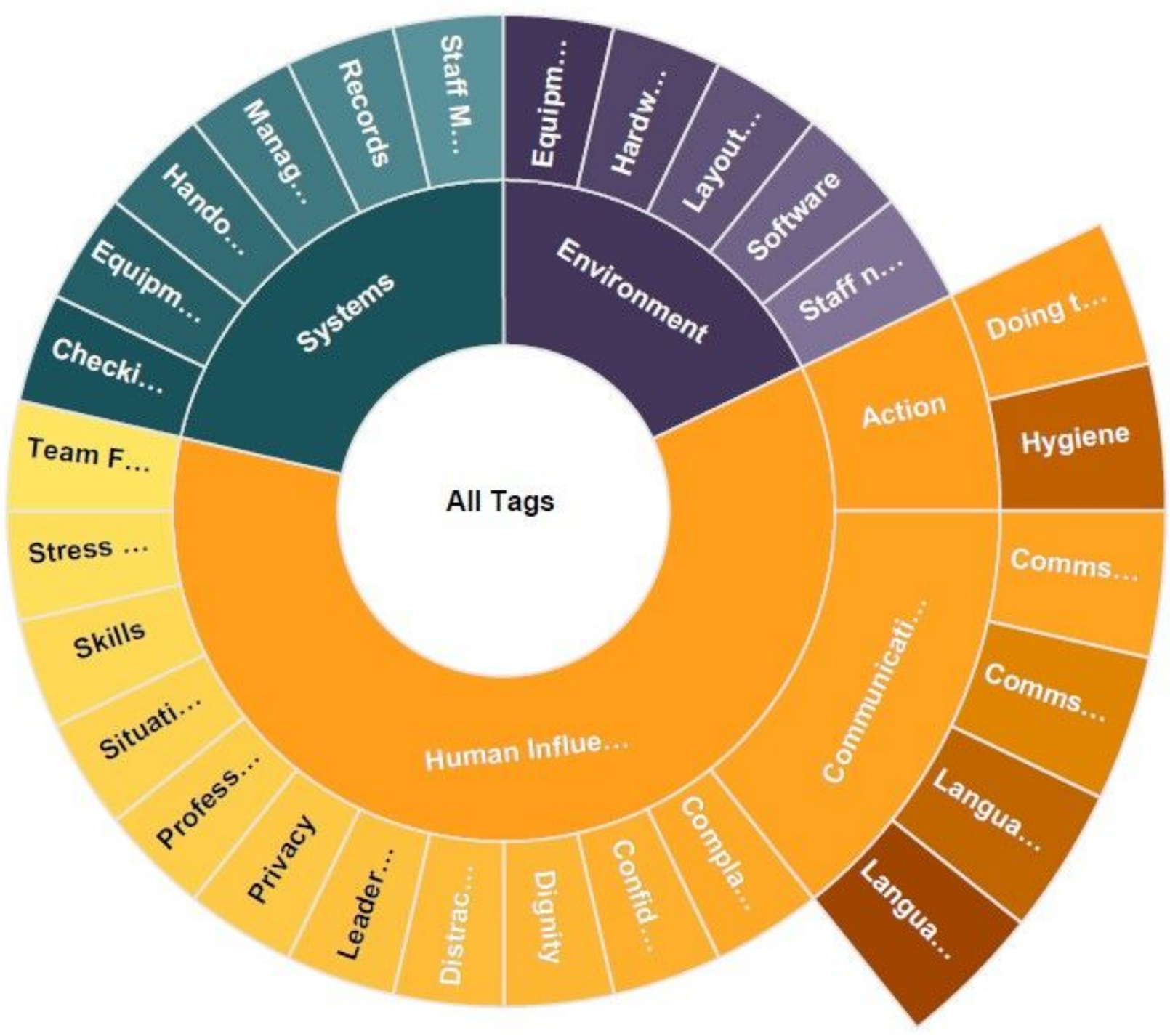

Figure 4

2C: Chart showing how to also present the data using all Tag headings

\section{Supplementary Files}

This is a list of supplementary files associated with this preprint. Click to download.

- EquatorReportingChecklist.docx 